\title{
Use of the Enteroscope for Colo-Ileoscopy: Low Yield in Unexplained Lower Gastrointestinal Bleeding
}

\author{
J. Belaiche, C. Van Kemseke, E. Louis \\ Dept. of Gastroenterology, Centre Hospitalier Universitaire Sart Tilman, University of Liège, Liège, Belgium
}

\begin{abstract}
Background and Study Aims: The small intestine is a potential origin of bleeding in patients with unexplained gastrointestinal tract hemorrhage or iron-deficiency anemia. Most reports on the investigation of these patients describe the use of upper tract enteroscopy. The diagnostic yield of combined upper and lower enteroscopy has not been widely assessed and remains to be clarified. The aim of this study was to assess the benefit of lower gastrointestinal tract enteroscopy in occult digestive bleeding.

Patients and Methods: Between 1 December 1995 and 15 January 1998, 54 patients with gastrointestinal bleeding of unknown origin were prospectively studied using upper and lower video push enteroscopy (44 for chronic iron-deficiency anemia and 10 for unexplained gastrointestinal tract hemorrhage with no potential site having been identified by other investigations). Examinations were done using a Olympus video enteroscope (SIF-100) under general anesthesia in a one-day clinic. An upper tract examination was done first, directly followed by the lower tract investigation.

Results: The upper tract enteroscopy was successful in 53 patients (98\%) and retrograde ileoscopy in 21 patients (39\%). In 18 (38\%) cases the technical failure resulted from the impossibility of intubating the ileocecal valve. A potential source of upper gastrointestinal bleeding was detected in $35 \%$ of patients with chronic irondeficiency anemia and in $20 \%$ of those with unexplained gastrointestinal tract hemorrhage. The most common lesion in the small bowel was angiodysplasia (25\%). The lower tract video push enteroscopy disclosed 11 lesions in patients with chronic anemia. However the lesions, including two ileocecal valve cancers, were mainly located in the colon and had been missed by previous colonoscopy. No case of ileal lesion was detected in this group of patients. In patients with unexplained gastrointestinal tract hemorrhage, three lesions were detected but only one of these was in the ileum. Associated colonic and jejunal lesions were observed in three patients (5.5\%). Overall, the diagnostic yield of lower video push enteroscopy was less than $2 \%$.

Conclusion: This prospective study has shown that using an enteroscope as a colonoscope in the management of patients with gastrointestinal bleeding of unknown origin is of little help. It might actually be more appropriate to perform a second colonoscopy. This however remains controversial and a prospective study is needed to answer that question.
\end{abstract}

\section{Introduction}

In patients with gastrointestinal blood loss and normal upper and lower gastrointestinal tracts the small intestine is a potential site of occult bleeding. Until recently, endoscopic exploration of the small bowel has remained relatively undeveloped. In recent years, several nonsurgical methods have been proposed for endoscopic exploration of the small intestine. The recent development of video push enteroscopy (VPE), by which it is possible to reach the distal jejunum, has replaced passive probe enteroscopy, a lengthly and difficult procedure [1-4]. Most reports concerning the investigation of occult gastrointestinal bleeds describe the use of upper tract enteroscopy [5-15]. Combined upper and lower tract VPE has been used principally by French teams and controversial results have been reported in two complete papers [16,17] and three abstracts [18-20]. The diagnostic yield of this combined procedure thus remains to be evaluated. The aim of this prospective study was to assess the benefits of lower tract VPE in the diagnosis of unexplained iron-deficiency anemia and gastrointestinal hemorrhage.

\section{Patients and Methods}

\section{Patients}

Between 1 December 1995 and 15 January 1998, 54 patients were prospectively studied using combined upper and lower tract VPE at our institution. Of the patients, 44 were investigated for chronic iron-deficiency anemia and 10 for gastrointestinal hemorrhage with no bleeding site having been identified by other investigations. All 
the patients had previously undergone endoscopic and radiological studies, including gastroscopy ( $\mathrm{n}=54)$, colonoscopy $(n=54)$, angiography $(n=13)$ and small bowel radiographs $(n=21)$. Most of these explorations had been carried out at other centers and patients had been referred for enteroscopy. The median age of the study group was $67.5 \pm 12.2$ (range 31-86), there were 26 men and 28 women.

\section{Endoscopic and Examination Technique}

All examinations were done using a Olympus video push enteroscope (SIF-100) with a total length of $247.5 \mathrm{~cm}$, a working length of $217.5 \mathrm{~cm}$ and an outer diameter of $11.3 \mathrm{~mm}$. The combined upper and lower digestive VPEs were done on a day-case basis. General anesthesia was used (propofol, sufentamyl and cisatracurium), with intubation to avoid aspiration because of the use of an overtube. The examination began with upper digestive tract investigation followed directly by lower tract exploration.

The upper tract VPE was carried out using the classical technique, with a gastric overtube. No fluoroscopy was done. The final extent of jejunal intubation was estimated by straightening the instrument to remove the gastric loop and subtracting $60 \mathrm{~cm}$ from the length inserted to the pylorus [8].

Lower tract enteroscopy was done as a colonoscopy, without an overtube after appropriate colonic preparation. The final depth of ileal intubation was estimated by the length of device introduced after the ileocecal valve had been passed.

Biopsies of duodenal and jejunal mucosa were systematically taken in patients with chronic anemia, using extralong standard biopsy forceps.

\section{Results}

\section{Enteroscopy Procedure}

The upper enteroscopy was successful in 53 patients (98\%). The procedure failed in one patient with chronic anemia who had a gastric ring for gastroplasty. The median depth of small intestinal intubation was $140 \pm 37 \mathrm{~cm}$ (range 50-210). The procedure took a median time of $30 \pm 10 \mathrm{~min}$ (range 10-60) to complete.

The lower tract enteroscopy was successful in 21 patients (39\%). The failures were caused by insufficient preparation in 12 patients $(22 \%)$ and tumorous ileocecal valves in three other patients $(5.5 \%)$. There were 18 (33\%) instances in which technical failure arose from the impossibility of intubating the ileocecal valve. The median depth of ileal exploration was $60 \pm 33 \mathrm{~cm}$ (range 5-100). The median duration of the exploration was $30 \pm$ 10 min (range 10-60).

There were no complications or postprocedure symptoms in any of the patients.

\section{Results of Upper Tract VPE}

A potential bleeding lesion was found by upper VPE in 15 of 43 patients (35\%) with chronic iron-deficiency anemia and in two patients (20\%) with unexplained gastrointestinal tract hemorrhage. The details of the lesions are summarized in Table 1 .

\section{Results of Lower Tract VPE}

In patients with chronic iron-deficiency anemia, the lower tract VPE revealed lesions in 11 cases. They were all located in the colon, and had been missed by previous colonoscopy. No case of ileal lesion was detected in this group of patients. The lesions comprised two cases of angiodysplasia, two ileocecal valve cancers, six hyperplastic polyps and one polyadenoma (Table 2).

In patients with unexplained gastrointestinal hemorrhage the lower tract VPE revealed a potential bleeding site in three cases. However, only one of these $(10 \%)$ was located in the ileum and arose from an aortoenteric fistula. In the two other cases the lesion was located in the colon, and had been missed by previous explorations. 
Table 1 : Results of upper gastrointestinal tract video push enteroscopy $\left(n=53^{*}\right)$

\begin{tabular}{lll}
\hline Patients and lesions & Total lesions \\
& $\mathrm{n}$ & $\%$ \\
\hline Chronic iron deficiency (43 patients) & 15 & 35 \\
Duodenojejunal lesions & 11 & 25.5 \\
Angiodysplasia & 2 & 4.5 \\
Jejunal polyp & 2 & 4.5 \\
Celiac disease & & \\
Unexplained gastrointestinal hemorrhage (10 patients) & 1 & 10 \\
NSAID jejunal ulcer & & \\
Previously missed lesions & 1 & 10 \\
Gastric ulcer & & \\
\hline
\end{tabular}

Failure of procedure in one patient. NSAID, nonsteroidal antiinflammatory drug.

Table 2 : Results of lower digestive video push enteroscopy $(n=54)$

\begin{tabular}{lll}
\hline Patients and lesions & \multicolumn{2}{c}{ Total lesions } \\
& $\mathrm{n}$ & $\%$ \\
\hline Chronic iron deficiency (44 patients) & 0 & \\
Ileal lesions & 11 & 25 \\
Previously missed colonic lesions & 7 & 16 \\
Polyp & 2 & 4.5 \\
Angiodysplasia & 2 & 4.5 \\
Ileocecal valve cancer & & \\
Unexplained gastrointestinal hemorrhage (10 patients) & 1 & 10 \\
Active ileal bleeding & 2 & 20 \\
Missed colonic lesions & 1 & 10 \\
Right diverticulum bleeding & 1 & 10 \\
lleocolonic anastomosis ulcer & &
\end{tabular}

Overall the diagnostic benefit of using an enteroscope as a colonoscope was less than $2 \%$ (one ileal lesion among 54 explorations).

Associated Lesions

Associated colonic and jejunal lesions were observed in three patients (5.5\%), including jejunal angiodysplasia and ileocecal valve cancer ( 1 patient), colonic and jejunal angiodysplasia (1 patient), and colonic polyp and jejunal angiodysplasia (1 patient).

\section{Discussion}

This prospective study of combined upper and lower gastrointestinal tract VPE in patients with unexplained chronic iron-deficiency anemia and hemorrhage demonstrates that the diagnostic benefit of lower tract VPE is very low (less than $2 \%$ ).

The novel aspect of this study was the assessment of the performance of lower gastrointestinal VPE, a procedure that has been little used until now, and almost exclusively done in France (Table 3). In fact, in the majority of studies evaluating VPE performance, lower enteroscopy was not done, as it was assumed that the majority of lesions would be located in the jejunum [5-15].

To answer the question of whether lower gastrointestinal VPE is really helpful in the management of patients with gastrointestinal bleeding of unknown origin, two points must be assessed. First, is the use of an enteroscope effective in intubating the ileocecal valve and progressing further into the ileum? Secondly, are significant 
lesions found in the ileum when it is successfully explored? As far as the first point is concerned, our study showed a technical failure rate of $33 \%$ for intubating the ileocecal valve. This is close to reports from previous studies $[16,17,19]$. The length of the scope and its smaller diameter render the lower tract enteroscope technically more difficult to use than a colonoscope. It is possible that in the future a mother-baby endoscope system could improve the procedure of ileocecal valve intubation [21]. On the other hand, a potential advantage of enteroscopy over colonoscopy is the length of ileum explored once it is reached. The median depth of ileal exploration in our series was $60 \mathrm{~cm}$, which again is very similar to that reported in previous studies $[16,17,19]$. Ideally the use of an enteroscope and a colonoscope should be compared in a prospective study of the exploration of the lower gastrointestinal tract in patients with unexplained digestive bleeding. As far as the second point is concerned, the diagnostic yield from investigating the ileum using the enteroscope was low in our study. Indeed, only one ileal lesion was disclosed in the 21 patients who had undergone a successful ileoscopy. This lesion was an aortoenteric fistula which was responsible for the bleeding. Although the diagnostic yield reported by Bouhnik and Bittoun [16] was higher, as almost 30\% of lesions were situated 30-80 $\mathrm{cm}$ proximal to the ileocecal valve, our results are comparable to those of Chollet et al. [19] and Landi et al. [17] who found, respectively, no ileal lesion in 33 examinations and one ileal lesion in 59 examinations (Table 3).

The diagnostic power of enteroscopy is further limited by the fact that any visualized lesions is not necessarily the source of the hemorrhage. This is particularly true for isolated angiodysplasias, and also in the case of noncancerous small polyp colonic lesions. In fact, it must be kept in mind that around 5\% of iron-deficiency anemias arising from occult gastrointestinal bleeds will recur, and remain occult in spite of repeated upper and lower tract explorations [22].

Table 3 Diagnostic efficacy of upper and lower video push enteroscopy in patients with anemia

\begin{tabular}{|c|c|c|c|c|}
\hline Authors & Patients (n) & Lesions $(\%)$ & Intestinal lesions $(\%)$ & $\begin{array}{l}\text { Previously missed gastric } \\
\text { or colonic lesions }(\%)\end{array}$ \\
\hline Croguenec et al. ${ }^{*}[18]$ & 150 & 83 & 83 & $?$ \\
\hline Chollet et al.* [19] & 66 & 27 & 12 (no ileal lesions) & 15 \\
\hline Bouhnik \& Bitoun [16] & 203 & 24 & 15 (includes $30 \%$ ileal lesions) & 9 \\
\hline Rolachon et al. * [20] & 34 & 67 & 38 & 29 \\
\hline Landi et al. [17] & 76 & 26 & 13 (includes $1.3 \%$ ileal lesions) & 13 \\
\hline Present study & 54 & 57.5 & 31 (includes $2 \%$ ileal lesions) & 26 \\
\hline
\end{tabular}

* Abstract

Overall, the main diagnostic benefit of lower enteroscopy in our study was related to previously missed colonic lesions (13/14 lesions disclosed). This was also the case in the previous studies with a range of missed colonic sites from 12 to $60 \%[7,10]$. In the series where upper and lower VPE was used the frequency varied from 9 to $29 \%[16,20]$.

The results from upper VPE in our study were similar to those previously reported in the literature, with jejunal an-giodysplasia being the lesion most frequently detected. It is also noteworthy that associated jejunal and colonic lesions were found in three patients $(5.5 \%)$. This should be kept in mind when a gastrointestinal bleed is attributed to a discovered upper or lower tract lesion.

In conclusion, this prospective study shows that using an enteroscope as a colonoscope was of little help in the management of patients with gastrointestinal bleeding of un-kown origin. This was because of the relative difficulty in intubating the ileocecal valve with the enteroscope and because of the relatively rare discovery of ileal lesions when using this procedure. In the future, a prospective study comparing the use of colonoscope for a repeat classic colonoscopy, with that of an enteroscope (possibly improved by new technology) should help to clarify the best approach in that clinical setting.

\section{Acknowledgement}

E. Louis is supported by the National Fund for Scientific Research (FNRS). 
Published in : Endoscopy (1999), vol.31, pp.298-301

Status: Postprint (Author's version)

\section{References}

1. Lewis BS, Waye JD. Chronic gastrointestinal bleeding of obscure origin: role of small bowel enteroscopy. Gastroenterology 1988; 94 : $1117-20$

2. Gostout CJ, Schroeder KW, Burton DD. Small bowel enteroscopy: an early experience in gastrointestinal bleeding of unknown origin. Gastrointest Endosc 1991; 37: 5-8

3. Morris AJ, Wasson LA, MacKenzie JF. Small bowel enteroscopy in undiagnosed gastrointestinal blood loss. Gut 1992; 33: 887-9

4. Van Gossum A, El Nawar A, Adler M, Cremer M. L'entéros-scopie: méthode et résultats. Acta Gastroenterol Belg 1992; 55: 169-75

5. Foutch GP, Sawyer R, Sanowski RA. Push-enteroscopy for diagnosis of patients with gastrointestinal bleeding of obscure origin. Gastrointest Endosc 1990; 36: 337-41

6. Barkin JS, Lewis BS, Reiner DK, et al. Diagnostic and therapeutic jejunoscopy with a new longer enteroscope. Gastrointest Endosc 1992; 38: $55-8$

7. Chong J, Tagle M, Barkin JS, Reiner DK. Small bowel push-type fiberoptic enteroscopy for patients with occult gastrointestinal bleeding or suspected small bowel pathology. Am J Gastroenterol 1994; 89: 2143-6

8. Davies GR, Benson MJ, Gertner DJ, et al. Diagnostic and therapeutic push type enteroscopy in clinical use. Gut 1995; 37: 346-52

9. Pennazio M, Arrigoni A, Risio M, et al. Clinical evaluation of push-type enteroscopy. Endoscopy 1995; 27: 164-70

10. Schmit A, Gay F Adler M, et al. Diagnostic efficacy of push-enteroscopy and long-term follow-up of patients with small bowel angiodysplasias. Dig Dis Sci 1996; 41: 2348-52

11.Askin MP, Lewis BS. Push enteroscopic cauterization: long term follow-up of 83 patients with bleeding small intestinal angiodysplasia. Gastrointest Endosc 1996; 43: 580-3

12. Rossini FP, Arrigoni A, Pennazio M. Clinical enteroscopy. J Clin Gastroenterol 1996; 22: 213-6

13. Vakil N, Huilgol V, Khan I. Effect of push enteroscopy on transfusion requirements and quality of life in patients with unexplained gastrointestinal bleeding. Am J Gastroenterol 1997; 92: 425-8

14. O'Mahony S, Morris AJ, Straiton M, et al. Push enteroscopy in the investigation of small-intestinal disease. Q J Med 1996; 89: 685-90

15. Chak A, Koehler S, Sundaram SN, et al. Diagnostic and therapeutic impact of push enteroscopy: analysis of factors associated with positive findings. Gastrointest Endoscopy 1998; 4: 18-20

16. Bouhnik Y, Bitoun A. L'entéroscopie: technique, indications, résultats. In: Colombel JF, Dupas JL, editors. Pathologie du grêle.Paris Doin éditeurs 1997: 63-71

17. Landi B, Tkoub M, Gaudric M, et al. Diagnostic yield of push-type enteroscopy in relation to indication. Gut 1998; 42: 421-5

18. Croguenec B, Canard JM, Houcke Ph, et al. Video enterosco-pie poussée par double voie (VE.P.) premier bilan (269 cas), (abstract). Gastroenterol Clin Biol 1995; 19: 2bis: A17

19. Chollet R, Benhamou Y, Luciani F, et al. L'entéroscopie puisée: une nouvelle technique endoscopique pour l'intestin grêle (abstract). Gastroenterol Clin Biol 1996; 20: 2bis: Al37

20. Rolachon A, Bonn B, Gueddah N, Fournet J. L.'entéroscopie poussée par double voie présente-t-elle un intérêt pour le diagnostic des lésions de l'intestin grêle? A propos d'une étude prospective (abstract). Gastroenterol Clin Biol 1998; 22: 2bis: A68

21. Jakobs R, Benz C, Maier M, et al. Transvalvular enteroscopy using a mother-baby endoscope system: a new approach to the distal ileum. Gastrointest Endosc 1997; 45: 298-300

22. Lau WY, Yuen WK, Chu KW, et al. Obscure bleeding in the gastrointestinal tract originating in the small intestine. Surg Gynecol Obstet 1992; 174: 119-24 